\title{
artículos
}

\section{El patrimonio industrial y los museos: evolución histórica y propuestas museísticas en europa}

\author{
Luz María Gilabert González 1
}

Universidad de Murcia

\section{RESUMEN}

La preservación del patrimonio arqueológico industrial, especialmente el arquitectónico, ha planteado en las últimas décadas la necesidad de darles nuevos usos para su correcta conservación. Una de las experiencias más interesantes desde este punto de vista ha sido la reconversión de antiguos edificios industriales en museos. En este estudio, se realiza un análisis histórico por las diferentes tipologías y modelos museísticos desarrollados en los distintos testimonios industriales de Europa.

PALABRAS CLAVE: Museo/ Patrimonio Industrial/ Europa.

The industrial heritage and the museums: historical evolution and offers for museums in Europe

ABSTRACT

The preservation of the industrial archaeology heritage, particularly architectural buildings, has raised the need to propose new uses for their proper preservation in the last decades. From this point of view, the redesigning of old industrial buildings into museums has been one of the most interesting experiences. This paper offers a historical analysis of the models and typologies of museums developed in the different industrial testimonies in Europe.

KEY WORDS: Museum/ Industrial Heritage/ Europe.

\section{IMPORTANCIA Y CONSERVACIÓN DEL PATRIMONIO INDUSTRIAL.}

Durante siglo y medio, el concepto de patrimonio se limitó a identificar como bienes patrimoniales sólo aquellos monumentos y objetos valorados por su carácter artístico o histórico, tal y como señalaba su clásica denominación ${ }^{2}$. Este concepto restringido, si bien favoreció la tutela y conservación de los monumentos, provocó la pérdida de numerosos testimonios dotados de capacidad documental por no ser considerados relevantes para la historia de la cultura. Tras la Segunda Guerra Mundial, se incluyó bajo un nuevo concepto de patrimonio, ahora llamado cultural, a todo un conjunto de tipologías exponentes de "civilización" que por su carácter social, por su valor para la identidad cultural o por su función de destino público eran dignos de ser protegidos 3 .

\footnotetext{
* GILABERT GONZÁLEZ, Luz María: "El patrimonio industrial y los museos: evolución histórica y propuestas museísticas en Europa", en Boletín de Arte, $n^{\circ} 30-31$, Departamento de Historia del Arte, Universidad de Málaga, 2009-2010, págs. 385-402. Fecha de recepción: Mayo de 2009.

1 Este trabajo es resultado de la ayuda (05137/FPI/06) concedida por la Fundación Séneca-Agencia de Ciencia y Tecnología de la Región de Murcia en el marco del II PCTRM 2007-2010.

2 El concepto de patrimonio histórico-artístico implica un juicio de valor amparado en criterios estéticos o históricos, que explicita la importancia que una obra u objeto reviste para el desarrollo del arte o de la historia.
} 
Esta nueva definición demostró un aumento en los parámetros con los que se medían los bienes patrimoniales, pasando a valorar no sólo aquellos objetos con significación histórica o artística, sino también a todos los elementos que como testimonio y documento de una época eran preciso conservar y difundir, ya que permitían un mayor conocimiento del pasado de la humanidad además de un reforzamiento de la memoria colectiva de la sociedad. Desde este punto de vista, los bienes de la industrialización pasaron a ser incluidos como una categoría más dentro del nuevo concepto de patrimonio cultural, evidenciando su necesidad de preservación y su puesta en valor.

Hoy el patrimonio industrial integra todos los restos materiales, formas y elementos del proceso industrializador capitalista, generados en el desarrollo histórico de los siglos XVIII y XX por las actividades productivas y extraídas del hombre, así como aquellos testimonios relativos a su influencia en la sociedad industrial ${ }^{4}$. Comprende una gama muy diversa de tipologías: monumentos, artefactos o máquinas, documentos y registros orales, como testimonios del pasado económico, técnico y social producido por la revolución industrial. Todo ello da como resultado un concepto de patrimonio industrial pluridisciplinar que tiende a asociarse de una forma muy estrecha con varias disciplinas y materias de conocimiento como la Arqueología, la Historia del Arte, la Etnografía y la Antropología. Una de las características principales de estos bienes patrimoniales es su relación con el lugar, tanto geográfica como topológicamente, pues la industrialización fue una consecuencia directa del uso que la sociedad hizo del medio físico. Esta vinculación se estableció por su natural dependencia con el entorno urbano o rural debido a la necesidad, por ejemplo, del suministro de materiales, de las fuentes de energía, del transporte o de la concentración de mano de obra. La estricta conexión funcional con el medio urbano llevó a formar autenticas ciudades industriales, que a veces se conectaron con otras o con los puntos de suministro o transporte, extendiéndose por todo un territorio llegando a formar verdaderos paisajes industriales ${ }^{5}$.

Pero para su valoración, el patrimonio industrial se enfrenta con enemigos muy poderosos, entre ellos, una frágil sociedad contemporánea que identifica la industria con experiencias vitales frecuentemente negativas: la contaminación, el trabajo, el ruido, etc. También, el hecho de dar la categoría de bien patrimonial a un

\footnotetext{
3 Por medio de la Ley del 26 de abril de 1964, el Parlamento italiano instituyó la Comisión Franceschini. Esta comisión emitió una declaración de principios en la que definió el "bien cultural" como "todo bien que constituya un testimonio material dotado de valor de civilización", al mismo tiempo, estableció un amplio elenco de las categorías de los objetos integrantes en los bienes culturales. GONZÁLEZ-VARAS, I.: Conservación de bienes culturales. Teoría, historia, principios y normas. Madrid, Cátedra, 2003, pág. 46.

4 ÁlVAREZ ARECES, M.A. (2006), "Musealización de espacios industriales: el patrimonio olvidado", en CALAF, R. y FONTAL, O. (coords.): Miradas al patrimonio, Gijón, pág. 327.

5 HUMANES, A.: "La necesidad de un plan para el patrimonio industrial", Bienes Culturales: Revista del Instituto del Patrimonio Histórico Español, nº 7, Madrid, 2007, pág. 46.
} 
conjunto de estructuras y objetos que han sido empleados por el hombre hasta fechas muy recientes tiene la desventaja de ser menos reconocible por una parte de los ciudadanos. Esta situación se traduce en la necesidad de un proceso de sensibilización social y de reconocimiento intergeneracional de unos elementos -desde el mínimo utensilio hasta el territorio-, como parte del bagaje cultural de la sociedad industrial y en los que poder proyectar unos valores históricos, estéticos y culturales como propios integrantes del patrimonio de la humanidad.

Una vez desaparecida la motivación económica y productiva que propulsó la construcción de los complejos industriales, se produjo el abandono y la demolición incontrolada de estos edificios fabriles. Fue en la década de los años setenta del siglo XX, cuando la sensibilización social por las ruinas industriales provocó la necesidad de buscar soluciones con propuestas de intervención fundadas en la idea no tanto de suprimir como de proteger y conservar las estructuras, edificios y espacios industriales abandonados 6 . Una idea que parecía aconsejable por varias razones: por su condición de vestigios del pasado con valor testimonial o como elementos de la arqueología industrial; por tratarse de un recurso con atractivos "per se", susceptible de actuar como reclamo cultural y, por tanto, de convertirse en producto turístico; y por operar como un factor de revitalización socioeconómica y de recuperación de la identidad para los territorios en crisis ${ }^{7}$.

Fue entonces cuando el edificio industrial comenzó a gozar de su nueva condición como monumento. Hasta ese momento sus transformaciones habían sido realizadas por las propias exigencias de la producción. Con el desuso de las instalaciones industriales éstas quedaron abiertas a nuevos cambios, pero ahora basados en la reutilización, la rehabilitación y la restauración como bienes del patrimonio industrial. Conceptos que no hacían referencia precisamente a servicios de primera necesidad ya superados, sino a mejoras ambientales, urbanas y sociales que pretendían conseguir una mejor calidad de vida de la sociedad posindustrial ${ }^{8}$.

Entre las posibles intervenciones que caben desarrollar en un edificio industrial para su salvaguarda, podemos distinguir entre aquéllas centradas en los aspectos puramente materiales o constructivos del mismo -conservación, consolidación y restauración- y las referidas a su uso -reutilización y rehabilitación- ${ }^{9}$. Sólo en el caso

\footnotetext{
6 En 1962, la destrucción de la estación de ferrocarril de Euston en Reino Unido fue la desencadenante de la sensibilización social y el nacimiento de una corriente de pensamiento sensible por el estudio y la preservación del patrimonio industrial que dará lugar a la gestación de una nueva disciplina científica: la Arqueología Industrial. Además, se sucedieron una serie de iniciativas por parte de las instituciones europeas e internacionales como la UNESCO.

7 BENITO DEL POZO, P.: "Patrimonio industrial y cultura del territorio", Boletín de la Asociación de Egresados y Graduados, $n^{\circ}$ 34, Perú, 2002, pág. 217.

8 El mejoramiento de la calidad de vida que se plantea como principal objetivo del desarrollo social, económico y cultural, pasa por la búsqueda necesaria de un equilibrio entre la calidad de los seres humanos y los recursos de su entorno.

9 CANO SANCHIZ, J.M.: "La fábrica de la memoria. La reutilización del patrimonio arqueológico industrial como medida de conservación", Antiqvitas, n 18-19, Córdoba, 2007, pág. 266.
} 


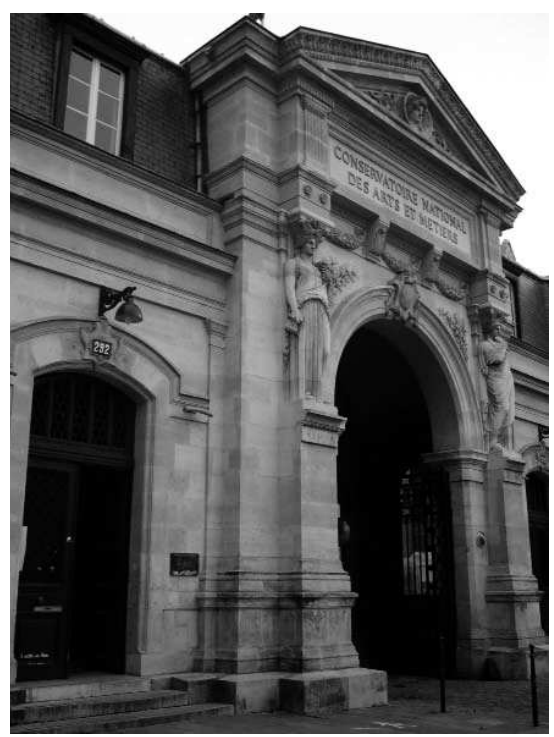

1. Fachada del Conservatorio Nacional de Artes y Oficios (París).

de elementos representativos a los que no se les puede aplicar ninguna función práctica, su intervención se limita a su restauración. En el resto de ejemplos, la actuación de naturaleza arquitectónica carecerá de sentido sino va acompañada de la reinstauración de una funcionalidad en el edificio porque "no es el principio de restauración como política primordial el que permitirá recuperar el espacio, pues un edificio o conjunto histórico que mantiene sus espacios obsoletos en los usos y con una rentabilidad no actualizada hace inviable la operación restauradora"10. Por tanto, sin una nueva función, independientemente de para qué usos, el inmueble está condenado a la degradación, incluso después de su restauración.

Es tal la libertad que caracteriza a las intervenciones en monumentos industriales que podemos considerar las distintas formas de actuación como interpretaciones diferentes de una misma manera de intervenir sobre una edificación existente. Por ello, la reutilización de un bien arqueológico industrial supone un esfuerzo de imaginación, que va desde soluciones que desean "vaciar" el complejo industrial hasta la opción más conservacionista que defiende la permanencia del legado industrial en su integridad. Entre ambas opciones extremas hay una gran diversidad de posibilidades e interpretaciones creando en la actualidad un panorama totalmente variopinto.

Sin duda, una de las experiencias más interesantes, desde el punto de vista de la conservación del patrimonio industrial y de su reutilización, es la renovación de

10 ÁLVAREZ ARECES, M.A.: "Musealización de espacios industriales: el patrimonio olvidado", en CALAF, R. y FONTAL, O. (coords.): Miradas al patrimonio. Gijón, Trea, 2006, pág. 339. 
antiguos espacios industriales en museos. En las últimas décadas, la musealización del patrimonio industrial ha significado importantes aportaciones en el campo de la museografía con una gran variedad de tipologías que van, desde aquellas iniciativas donde el edificio industrial da sede a su propio museo, a otras posibilidades museográficas donde la colección no guarda ninguna relación con el sector industrial al que pertenecía la fábrica. En este sentido, la museología juega, por un lado, con la amplia gama de edificios que engloba la arquitectura industrial y, por otro, con la relación de interdependencia que tiene el monumento con su entorno y con su función productiva; ofreciendo un extenso abanico de modelos diferentes fruto de las interpretaciones que bajo el concepto de museo se pueden hacer del patrimonio industrial.

\section{EVOLUCIÓN hISTÓRICA DE LOS MUSEOS INDUSTRIALES.}

Para hablar de la musealización de edificios y sitios de arqueología industrial es necesario realizar un repaso histórico a partir de los objetos de la industria que representaron, a finales del siglo XVIII, el primer motor del interés por la museología técnico-científica, para entender cómo se llegó a la necesidad de salvar los edificios industriales e incluso conservar sus propios contextos territoriales. Comenzamos este recorrido desde el nacimiento de los museos especializados en la ciencia y la tecnología hasta la creación de parques industriales.

Los primeros museos de ciencia y tecnología.

El testimonio de un primer interés y aprecio hacia la técnica y las artes industriales se encuentra ya en la Francia revolucionaria efectuando una labor pionera en los procesos de musealización de espacios industriales. El llamado Conservatorio Nacional de Artes y Oficios de París, fundado por el abad Grégoire en 1794 e inaugurado ocho años después, fue el primer museo público de la técnica, la ciencia y la industria, y un precioso testimonio del nacimiento de la museografía técnica y científica ${ }^{11}$ [1]. La preocupación de su creador era la de revalorizar las artes mecánicas facilitando el intercambio y la difusión de los inventos y los usos industriales, a los que el corporativismo gremial, todavía muy poderoso, impedía su difusión ${ }^{12}$.

Instalado en el priorato de Saint Martin des Champs -un complejo edilicio medieval con una serie de construcciones realizadas en el siglo XVIII-, fue reformado por el arquitecto Leon Vaudoyer, entre 1838 y 1872, para sistematizar el museo

\footnotetext{
11 CORRAO, M.: Musealizzazione dell'archeologia industriale. Materiali bibliografi. Palermo, Biblioteca Centrale della Facoltà di Architettura di Palermo, 2003, pág. 12.

12 BOLAÑOS, M.: Historia de los museos en España: memoria, cultura y sociedad. Gijón, Trea, 1997, pág. 262.
} 


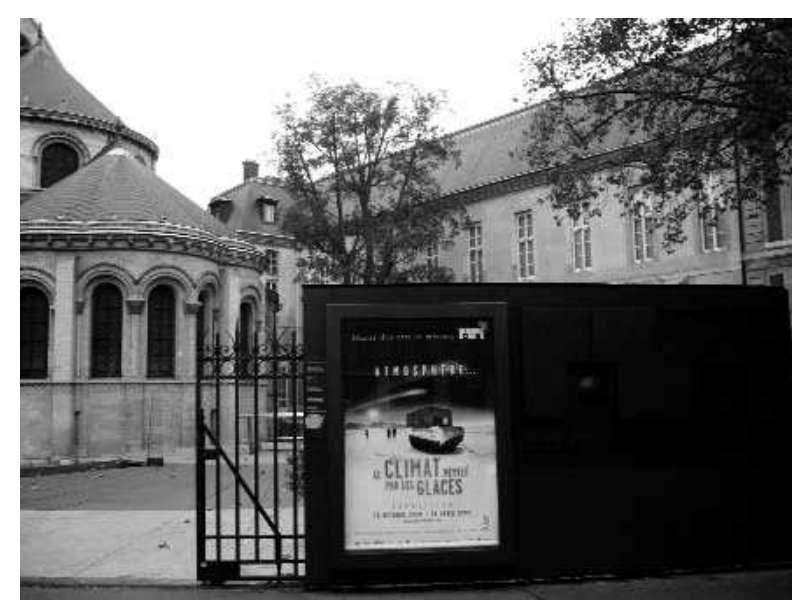

2. Entrada del actual Museo de las Artes y los Oficios (París).

dando cuerpo a la idea de un "templo laico de la época positivista", a través de las transformaciones de la iglesia en sala de máquinas y del comedor en biblioteca ${ }^{13}$ [2]. La administración francesa salida de la Revolución del 89, impulsará un movimiento de creación de museos de artes decorativas e industriales que se extenderá por las provincias de Francia ${ }^{14}$.

En Inglaterra también se produjo el debate sobre la exposición de objetos industriales. En este contexto, sir Henry Cole funda, en 1852, el Museo Kensington para dar permanencia a la colección de los productos de la industria contemporánea que habían sido exhibidos en la recién concluida Exposición Universal celebrada en Londres. En 1856, bajo el nombre de Museo Nacional de Arte y Diseño, la colección industrial pasa a ser instalada en un edificio de hierro y cristal acorde con la modernidad de los objetos, y en 1899, la institución será rebautizada pasando a llamarse como Museo Victoria y Alberto, en homenaje a la reina y su esposo, convirtiéndose en el museo de artes decorativas más grande del mundo.

La fórmula londinense tuvo un éxito fulgurante y, entre 1860 y 1880 , numerosas capitales europeas se prestaron a reproducir la idea, si bien, en muchos casos fue debida a la iniciativa privada: Viena crea el Museo Nacional de la Ciencia y la Industria

13 CORRAO, M.: Musealizzazione dell'archeologia industriale. Materiali bibliografi. Palermo, Biblioteca Centrale della Facoltà di Architettura di Palermo, 2003, pág. 12.

14 El primero de ellos fue el Salón de las Flores en el Museo de Bellas Artes de Lyon (1801), continuado con el Museo de Cerámica en Sévres y Limoges (1853), la Galería de Encaje en Puy (1854) y el Museo de Porcelanas en Nevers (1872). 
(1863) y, Hamburgo y Berlín abren sus museos de ciencia y tecnología en 1872 y 1881 respectivamente. Todos estos ejemplares europeos tendieron a responder a una doble vocación que aúna la idea de museo como guardián y testimonio de las industrias del pasado y muestra la vitalidad de los productos tecnológicos modernos ${ }^{15}$.

Los museos al aire libre.

En 1891 nació en Suecia el concepto de museo al aire libre, concretamente, en la sección al abierto de Skasen del Museo Nórdico de Estocolmo, fundado por Arthur Hazelius. En el Museo Skansen, Hazelius mostraba las viviendas rurales más representativas del paisaje sueco que fueron trasladadas de su emplazamiento originario y acondicionadas con un mobiliario adecuado a su época histórica, tratando de recuperar y documentar la tradición etnoantropológica del pueblo sueco: la vida, la producción, la actividad, el folklore, la arquitectura y el entorno. Paradójicamente, esta necesidad nació como reacción a la globalización y la homogenización de la revolución industrial, es decir, el miedo a la pérdida definitiva de las tradiciones de la vida cotidiana y de las costumbres locales que se encontraban en riesgo de desaparecer.

Con una nueva forma de exposición original e inédita frente al modelo clásico de finales del siglo XIX, el museo pasó a tener "tres dimensiones"16 -rompiendo con la simple secuencia de objetos en la pared- y se transformó en un lugar donde era posible vivir una experiencia espacial completa y capaz de ofrecer un testimonio creíble del mundo rural. Tras esta iniciativa, aparecieron otros museos al aire libre en algunos países del norte de Europa como los de Oslo en Noruega (1894), de Lyngby en Dinamarca (1901), de Turku en Finlandia (1906) y de Arnhem en Holanda (1912), sucediéndose una cadena de fundaciones en los Países Bajos, Alemania y, sobre todo, en los Países del Este.

\section{Los modernos museos de industria: nuevas tipologías.}

La creación de los museos al aire libre en los países escandinavos habían tenido la necesidad de resolver determinados aspectos prácticos que, según Lopes Cordeiro, hoy en día se englobarían en la museografía industrial17. Pero en realidad, ésta comienza a afirmarse plenamente después de la década de 1960, como una emergencia de los modernos museos industriales surgidos a consecuencia del desarrollo de la Arqueología Industrial -como disciplina académica- y el despertar de una conciencia social por conservar estos testimonios, especialmente en aquellas regiones europeas donde con más fuerza se había sentido la revolución industrial.

15 BOLAÑOS, M.: Historia de los museos en España: memoria, cultura y sociedad. Gijón, Trea, 1997, pág. 266.

16 CONTI, G.: La nuova cultua del recupero. Bologna, Clueb, 1995, pág. 141.

17 LOPES CORDEIRO, J. M.: "Museología y museografía industrial”, en ÁLVAREZ ARECES, M. A. (coord.): Arqueología Industrial, Patrimonio y Turismo Cultural. Gijón, Trea, 2001, pág. 47. 
Es entonces cuando se desencadena una revisión de los planteamientos que subyacen a los viejos museos de la ciencia y de la técnica, dejando de ser meros testimonios del progreso para pasar a prestar una mayor atención a la dimensión humana de la industrialización, al tiempo que se desarrollaron nuevas concepciones museísticas con el fin de recuperar el patrimonio industrial de Europa ${ }^{18}$.

Además, los cambios operados por la Nueva Museología se dejaron sentir en las nuevas funciones que debían cumplir los museos. A las tradicionales funciones de salvaguarda y protección del patrimonio cultural se añadió un nuevo cometido al servicio de la sociedad, contribuyendo a programas de desarrollo social y económico de sus comunidades, y llegando incluso a transformarse en un recurso para el aprovechamiento turístico. Surgen así los museos centrados expresamente en la difusión y comprensión de los restos materiales de la industrialización, fundamentados en la creación de ecomuseos y la musealización "in situ" de estructuras e instalaciones industriales. Los museos de sitio ${ }^{19}$ tratan de musealizar en su lugar de origen los viejos edificios de la industrialización con colecciones puntuales y concretas referidas a un único centro productivo, y con la finalidad de mostrar y hacer compresibles sus contenidos como testimonio del ambiente económico, técnico y social de la época en que se encontraban en funcionamiento. Esta tipología de museo industrial se concretó por primera vez en el Museo de Ironbridge, emplazado en el valle del río Severn, región que fue el principal centro de producción de Gran Bretaña. En 1968 se creó una fundación para la recuperación del patrimonio industrial del valle, preservando a lo largo de doce kilómetros todos los emplazamientos industriales y sus técnicas de producción. Comenzaron con la restauración de un puente del siglo XVIII y, en 1979, se inauguró un museo del hierro. Poco tiempo después, se concretó la reconstrucción de un pueblo típico de la época victoriana y se restauraron dos caserones y varias viviendas obreras. Además se transformaron en museos la fábrica de cerámica de Jackfield y la de porcelana de Coalport20.

Posteriormente, los museos de sitio se extendieron por todos los países desarrollados y su número fue creciendo de forma espectacular siendo hoy la tipología más abundante de museo industrial. El ejemplo más emblemático es la planta de siderurgia Völklingen (Alemania), que fue el mayor emporio manufacturero de perfiles metálicos del país y tras su cierre, en 1986, se conservaron todos los elementos del sistema productivo, siendo declarada por la UNESCO como Patrimonio de la Humanidad en 1994.

Un paso más hacia la conquista de nuevos modelos museísticos se producirá

18 BENITO DEL POZO, P.: "Patrimonio industrial y cultura del territorio", Boletín de la Asociación de Egresados y Graduados, n 34, Perú, 2002, pág. 218.

19 Según el ICOM, el museo de sitio está concebido y organizado para proteger un patrimonio natural y cultural, mueble e inmueble, conservado en su lugar de origen, allí donde este patrimonio ha sido creado o descubierto.

20 CONTI, G.: La nuova cultura del recupero. Bologna, Clueb, 1995, pág. 142. 
en Francia con la creación de un nuevo tipo de institución conocida con el nombre de ecomuseo. Una tipología basada en la idea de conservar y presentar "in situ" los elementos patrimoniales de un territorio y donde la comunidad local es una activa participante en el proyecto de musealización. Consiste en un proceso dinámico de desarrollo local y de ordenación territorial integral, que recupera ambientes y paisajes industriales para actividades de ocio y consumo enfocadas a dinamizar zonas deprimidas o en crisis a través de tres pilares fundamentales: la población, el territorio y el patrimonio. De esta forma, en el concepto de ecomuseo subyacen los principios básicos de la Nueva Museología: territorialidad del campo de intervención, servicio a la comunidad y activa participación de la población local21. Además, ofrece nuevas posibilidades frente al concepto tradicional de museo porque representa un proyecto abierto, participativo e integrador que se extiende por un territorio donde se ponen en valor tanto sus elementos como sus identidades culturales y naturales, y que necesita de la participación del público como de la población autóctona para desarrollarse. Así, frente al convencional concepto de edificio como contenedor del museo, se prefiere el de territorio -como estructura descentralizada-; el de patrimonio -material e inmaterial, natural y cultural- sobre el término tradicional de colección; y el de comunidad -desarrollo de una sociedad concreta- sobre el indeterminado de público 22 .

La primera experiencia en este tipo de intervenciones se produjo, entre 1971 y 1974, en Le Creusot-Montceau-Les Minessobre, un territorio de trescientos noventa kilómetros cuadrados y con una población de mil habitantes, al sur de la región de Borgoña. El proyecto ideado por Marcel Evrard 23 y en colaboración con la población tenía la finalidad de reactivar una importante zona minera y de siderúrgica que decayó en los años setenta. Para llevarlo a cabo, se reutilizaron los edificios con valor patrimonial para museos, escuelas-taller o itinerarios, y se recuperó el medio ambiente para ir recreando las formas de vida y de trabajo tradicionales. La sede del museo se estableció en el Château de la Verrerie, una vieja fábrica real de vidrios del siglo XVIII, y desde aquí se coordinaba la visita por una serie de edificios repartidos en dos conjuntos de actividades: el de las industrias metalúrgicas y del transporte en Le Creusot, y el de las extractivas del carbón y sus industrias derivadas en Montceau. Así, "se configuró un museo del tiempo y del espacio, un laboratorio in situ, realizado por la propia comunidad y dirigido por tres comités: usuarios, administradores y personal especializado"24.

Esta nueva generación de museos industriales se acompañará, ya en la déca-

\footnotetext{
21 CORRAO, M.: Musealizzazione dell'archeologia industriale. Materiali bibliografi. Palermo, Biblioteca Centrale della Facoltà di Architettura di Palermo, 2003, pág. 14.

22 ALONSO FERNÁNDEZ, L.: Museología y museografía. Barcelona, Ediciones del Serbal, 1999, págs. 102103.

23 Con el apoyo de Hugues de Varine-Bohan y Georges Henri-Rivière, ambos realizaron una definición de ecomuseo referida a sus diferencias con los museos tradicionales.

24 HERNÁNDEZ HERNÁNDEZ, F.: Manual de Museología. Madrid, Síntesis, 1994, pág. 74.
} 
da de los años ochenta, con otro fenómeno denominado como turismo cultural, que dará lugar al nacimiento de otro tipo de experiencias sobre la recuperación del patrimonio industrial conocidas como parques patrimoniales. Un parque patrimonial puede considerarse como un proyecto que intenta unir recursos culturales a partir de una historia motriz territorial, con un sentido de coherencia y estructuración mediante una hipótesis de interpretación de un episodio relevante de la historia, y avanzar unos criterios para la ordenación de un territorio y para la gestión correcta de sus recursos 25 . Como ejemplos de parques patrimoniales encontramos a los parques temáticos mineros, los complejos portuarios y los valles industriales. Todas estas iniciativas buscan contribuir a la disminución del impacto negativo producido por la crisis industrial de ciertas áreas de Europa, cuyos territorios son identificados con actividades productivas y que contienen multitud de recursos patrimoniales, culturales y naturales significativos que pueden ser explotados para fines culturales y turísticos generando así un nuevo desarrollo económico local. En estos casos, se trata de dar una mayor valoración a la adecuación del lugar y una puesta en valor del patrimonio a escala territorial quedando integrado dentro de programas de ordenación del territorio. También, se trata de salvaguardar todo tipo de elementos del patrimonio más significativo para la identidad de las comunidades que vivieron y trabajaron en estas zonas.

Dentro de este panorama museístico también debemos resaltar la importante propuesta de Cataluña. En 1984 inauguró su Museo de la Ciencia y de la Técnica ${ }^{26}$, instalado en un antiguo vapor textil lanero de Tarrassa -la fábrica Aymerich, Amat i Jover- construido por Luis Muncunill en estilo modernista. Este museo fue el germen y la sede central de una red formada actualmente por dieciocho museos industriales catalanes. EI mNACTEC tiene como objetivos principales la presentación del patrimonio industrial y la difusión de la historia de la industrialización, de la ciencia y de la técnica como componentes culturales. Con diferentes dependencias, el espacio principal es la gran nave de producción donde se presentan las exposiciones permanentes sobre el transporte, la energía, el proceso industrial de la lana, la historia tecnológica desde la revolución neolítica hasta la industrialización y el desarrollo de la arquitectura industrial de Luis Muncunill.

El Sistema Territorial de Museos de la Ciencia y la Tecnología de Cataluña es, según Pardo Abad, un modelo de referencia obligada en la museografía indus-

25 Según la acepción que le dan los profesores Schuster y Sabaté del MIT de Massachussets y el Departamento de Urbanismo y Ordenación del Territorio de la Universidad Politécnica de Cataluña. ÁLVAREZ ARECES, M.A.: "Musealización de espacios industriales: el patrimonio olvidado", en CALAF, R. y FONTAL, O. (coords.): Miradas al patrimonio, Gijón, Trea, 2006, pág. 332.

26 En 1979 nace la Asociación del Museo de la Ciencia y la Técnica de Arqueología Industrial de Cataluña por la Asociación de Ingenieros Industriales de Cataluña, que desde finales del siglo XIX habían buscado la creación de un Museo de la Ciencia y la Técnica, y para preservar los bienes del patrimonio industrial. En el año 1982, el Departamento de Cultura de la Generalitat asumió el proyecto y en 1983 adquirió la fábrica para convertirla en un museo de la ciencia y la técnica. En 1990, el Museo de la Ciencia y Tecnología de Cataluña es declarado Museo de Interés Nacional por tener una significación especial para el Patrimonio Cultural de Cataluña -según el artículo 25 de la Ley 17/1990, de 2 de noviembre, de Museos-. De esta forma, pasa a ser a ser una entidad autónoma y se convierte en la sede central del Sistema de Museos de la Ciencia y la Tecnología promovido por la Generalitat de Cataluña. AGUILAR, I.: "Restauración del patrimonio arqueoló- 
trial por la riqueza de sus colecciones, por la descentralización territorial planteada por toda la Comunidad Autónoma y por la variedad de arquitecturas industriales rehabilitadas $^{27}$. Los museos del sistema están especializados en diferentes aspectos de la ciencia y la tecnología, algunos de temática única en torno al papel, al corcho o al ferrocarril y otros dedicados al proceso de industrialización de la zona en que se encuentran. Pero todos ellos están enmarcados en su contexto histórico y territorial para explicar uno de los principales activos de la cultura catalana contemporánea. Además, están instalados en viejas construcciones industriales -fábricas, molinos, depósitos de agua o ferrerías-, que son recuperados para dotarlos de un nuevo uso museístico. En definitiva, se trata de una serie de museos que aportan un gran valor patrimonial y paisajístico a su entorno local, convirtiéndose en puntos de gran atracción turística con las repercusiones sociales y económicas que ello implica.

\section{Otras propuestas museisticas en EDIFICIOS INDUSTRIALES.}

Más allá de las actividades ejercidas por los museos industriales encontramos otras respuestas museísticas para la salvaguarda del patrimonio industrial edificado. Desde la década de 1980, se ha producido en las grandes ciudades de Europa un reaprovechamiento de viejas fábricas y ruinosos almacenes para equipamientos culturales. Son básicamente experiencias basadas en la reutilización de inmuebles industriales donde se exponen colecciones de arte no vinculadas directamente con el edificio o con el sector industrial al que pertenecía la fábrica y en cuya transformación se tiende a vaciar el monumento de todo contenido industrial que albergaba, impidiendo que sean reconocidos, desde su interior, su función como edificio industrial.

Son museos en los que se le ha dado todo el protagonismo a la arquitectura en sí, siendo remodelados por un "impulso estético-protector", ya que la mayoría de ellos son notables ejemplos de la arqueología industrial declarados como monumentos de interés histórico o artístico, susceptibles por tanto de ser conservados y reutilizados. Además, las distintas tipologías fabriles de la industrialización facilitan todo tipo de cambio por su enorme capacidad para aceptar nuevos usos debido a su estructura abierta, articulada y flexible, a sus espacios funcionales y de planta libre, así como a sus sistemas de comunicación claramente establecidos o fácilmente transformables. Estas características arquitectónicas han favorecido su reutilización especialmente para la creación de museos con colecciones de arte moderno y contemporáneo. Sus edificios han sido dotados de espacios de sociabilidad y de servicio público con la incorporación de cafeterías, librerías, salas para actividades, auditorios, etc., que responden con el nuevo concepto de museo surgido a finales del siglo XX. Frente a ellos,

gico industrial", en GUTIÉRREZ, R., CASTRO, F. y MARTíN, M. (coords.): Preservación de la Arquitectura Industrial en Iberoamérica y España. Granada, Instituto Andaluz del Patrimonio Histórico, 2001, pág. 167.

27 PARDO ABAD, C.J.: "La reutilización del patrimonio industrial como recurso turístico. Aproximación geográfica al turismo industrial”, Treballs de la Societat Catalana de Geografia, n 57, Barcelona, 2004, pág. 14. 
aparecen otros espacios contemporáneos de nueva planta, diseñados en su mayoría por arquitectos de reconocido prestigio que buscan la reactivación de zonas industriales degradadas como es el caso del Museo Guggenheim de Bilbao.

\section{El Museo de Orsay (París).}

La estación de tren creada para la Exposición Universal de 1900 por Victor Laloux fue el edificio elegido por la Dirección de Museos de Francia para albergar el Museo de Orsay (París), donde estarían representadas todas las artes desde 1848 hasta 1914. En 1978, la estación fue declarada como Monumento Histórico y la nueva institución fue abierta al público en 1987 con la transformación realizada por los arquitectos Bardon, Colboc y Philippon pertenecientes al grupo ACT-Architecture. Su proyecto pretendía, ante todo, respetar la arquitectura de Victor Laloux, a la vez, que reinterpretarla en función de su nueva vocación ${ }^{28}$ [3].

A pesar de la coetaneidad entre el continente y el contenido, el acondicionamiento interior supuso la elaboración de un programa interdisciplinar protagonizado por la arquitecta Gae Aulenti y el museólogo Michel Laclotte. Una de las características de este museo es su proyección enciclopédica al querer integrar en un mismo edificio todas las manifestaciones de una misma época: escultura, pintura, artes decorativas, mobiliario y fotografía. La presentación unificada, dentro de una gran diversidad de volúmenes desmesurados de la estación, permite resaltar la gran nave abovedada, utilizándola como eje principal del recorrido y transformar la marquesina del exterior en entrada principal [4].

La nave central funciona como una gran avenida donde se exponen las esculturas a ambos lados, delimitada por una serie de paramentos que rememoran la arquitectura egipcia y, como cerramiento del espacio, dos torres dedicadas a las obras del Art Nouveau. En el nivel intermedio de terrazas y salas laterales se exponen las pinturas, el mobiliario y las artes decorativas, y en el tercer nivel se suceden una serie de salas dedicadas a la pintura impresionista y posimpresionista junto con litografías, dibujos y fotografías.

Para Santos Zunzunegui, la transformación en museo de la Estación Orsay es un ejemplo de lo que él denomina "museo posmoderno", donde el continente se integra totalmente con el contenido, produciéndose a su vez, un proceso de "resemantización" que hace que se recuerde constantemente el uso que el edificio tuvo anteriormente. Dicha concepción espacial implica una nueva manera de ver y de contemplar el arte, pues no se trata de un recorrido lineal, sino libre y fragmentario en el que el visitante se abre constantemente a nuevas sensaciones, superando así la visión del museo tradicional 29 .

28 MATHIEU, C.: Orsay. L'espirit du lieu. París, Scala, 2007, págs. 37-40.

29 HERNÁNDEZ HERNÁNDEZ, F.: Manual de Museología. Madrid, Síntesis, 1994, pág. 180. 

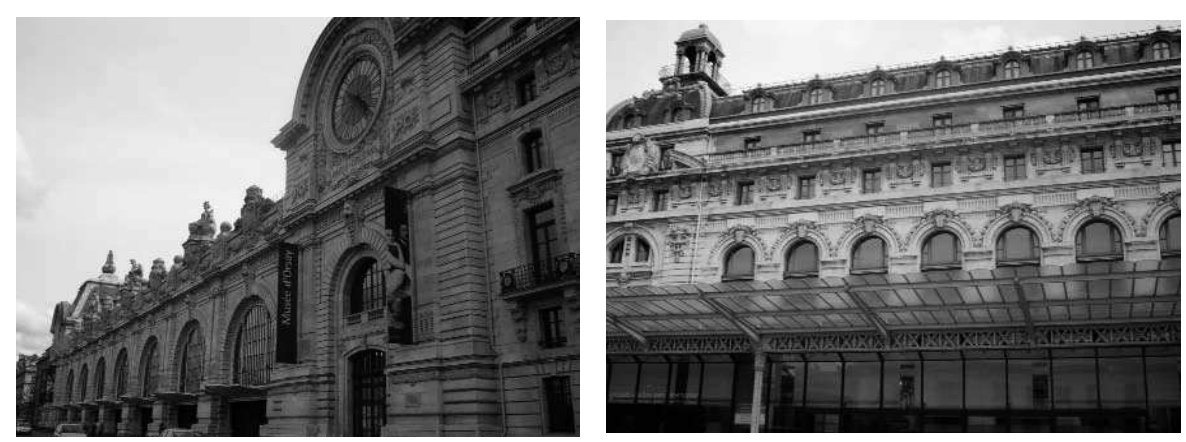

3. Fachada lateral del Museo de Orsay (París).

4. Fachada de la entrada principal del Museo de Orsay (París).

\section{EI Museo de Arte y de Industria (Roubaix).}

El Museo de Arte y de Industria fue creado en 1889 y tras varias vicisitudes volvió a renacer en el año 2000 al trasladarse a una nueva sede. El edificio elegido fue la antigua piscina municipal de Roubaix construida por Albert Baert, entre 1927 y 1932, en estilo Art-Decó y cuya delicada decoración le llevó a ser considerada como la piscina más bella de Francia. Jean-Paul Philippon fue el encargado de reconvertir el inmueble en museo, ubicando la colección textil en la gran nave de planta basilical de la piscina central, donde diseñó en el centro una pasarela para realizar desfiles, y las obras de bellas artes de los siglos XIX y XX fueron dispuestas en otros espacios del edificio.

\section{La Fundación Antoni Tàpies (Barcelona).}

La Fundación Antoni Tàpies abrió sus puertas, en 1990, en la sede de la antigua Editorial Montaner y Simón (1881-1885). Era un edificio construido por Lluís Doménech y Montaner en una fase temprana del Modernismo catalán, y siendo éste el primer inmueble del Ensanche barcelonés que integraba la tipología y la tecnología industrial -combinando hierro y ladrillo visto- en el tejido del centro urbano.

El artista Antoni Tàpies eligió esta construcción como sede de su fundación porque le atraía la modernidad de su estructura, sus cualidades espaciales y su carácter templario. Estas características le sirvieron para plantear un tipo de espacio expositivo de arte contemporáneo ecléctico -desde el punto de vista museográfico-, frente al paradigma de neutralidad que suele reinar en estos espacios. Entre 1987 y 1990, los arquitectos Roser Amadó y Lluís Domènech Girbau se encargaron de la restauración y de la transformación de la editorial para su nuevo destino. El edificio 
con diferentes niveles abarca la percepción de la doble altura de las salas de exposición y biblioteca, y su estructura -dividida por medio de columnas de fundición- permite dotar a las salas de un carácter abierto y flexible ${ }^{30}$.

\section{El Museo Nenes Weserburg (Bremen).}

En 1991 fue creado el Museo Nenes Weserburg de Bremen (Alemania), un complejo industrial en cuyo interior se exponen hoy las obras de varias corrientes artísticas internacionales de los últimos cuarenta años, convirtiéndose en uno de los museos de arte contemporáneo más importantes del país. El complejo edilicio está formado por cuatro enormes almacenes portuarios utilizados para la torrefacción de café hasta los años setenta. Tras la suspensión de la producción pasó a ser propiedad de la ciudad y fue empleado como espacio expositivo por varias instituciones culturales hasta que fue creada, en 1988, una fundación privada para crear este museo ${ }^{31}$. Los almacenes fueron construidos, en 1897, con un estilo neogótico flamígero y cuyo aspecto exterior respondía a la forma característica de los establecimientos con techos en punta típicamente medievales de las ciudades de la Alemania del Norte. La transformación para su nuevo uso museístico fue encargado al arquitecto Wolfram Dahms. En su proyecto, la arquitectura industrial quedó al servicio de la nueva función que ejercería el museo, sin tener en cuenta el uso precedente o la estructura de los almacenes, a menos que estos fuesen indispensables desde el punto de vista constructivo. Por ello, la transformación interior fue total con la intención de crear espacios idóneos para la exposición de obras de arte contemporáneas, respondiendo al espacio museográfico del siglo XX conocido como "cubo blanco" con ambientes neutros, bien proporcionados y muy luminosos.

\section{La Tate Modern (Londres).}

En la ribera sur del Támesis frente a la Catedral de San Pablo se encuentra la antigua central eléctrica Bankside transformada hoy en una de las galerías de arte contemporáneo más importante del Reino Unido y una de las más visitadas del mundo. La central fue construida, entre 1947 y 1963, por sir Gilbert Scout y su exterior estaba caracterizado por paredes de ladrillo visto con haces de ventanas altas y estrechas, y rompiendo visualmente con la horizontalidad del edificio se levantó una chimenea de planta cuadrada de casi cien metros de altura [5].

La intervención para su reutilización, llevada a cabo por los arquitectos sui-

30 LAYUNO ROSAS, M.A. Museos de arte contemporáneo en España. Del "palacio de las artes" a la arquitectura como arte. Gijón, Trea, 2004, págs. 343-344.

31 Junto con la Galería Städtische en el Buntentor de Bremen (Alemania), la Central Montemartini de Roma (Italia), el Museo de la Electricidad de Lisboa (Portugal) y el Museo de Arte y de Industria de Roubaix (Francia) integran el proyecto europeo Euromusées 2001 para gestar la base de una red en Europa de instituciones museísticas creadas en edificios de arqueología industrial. 

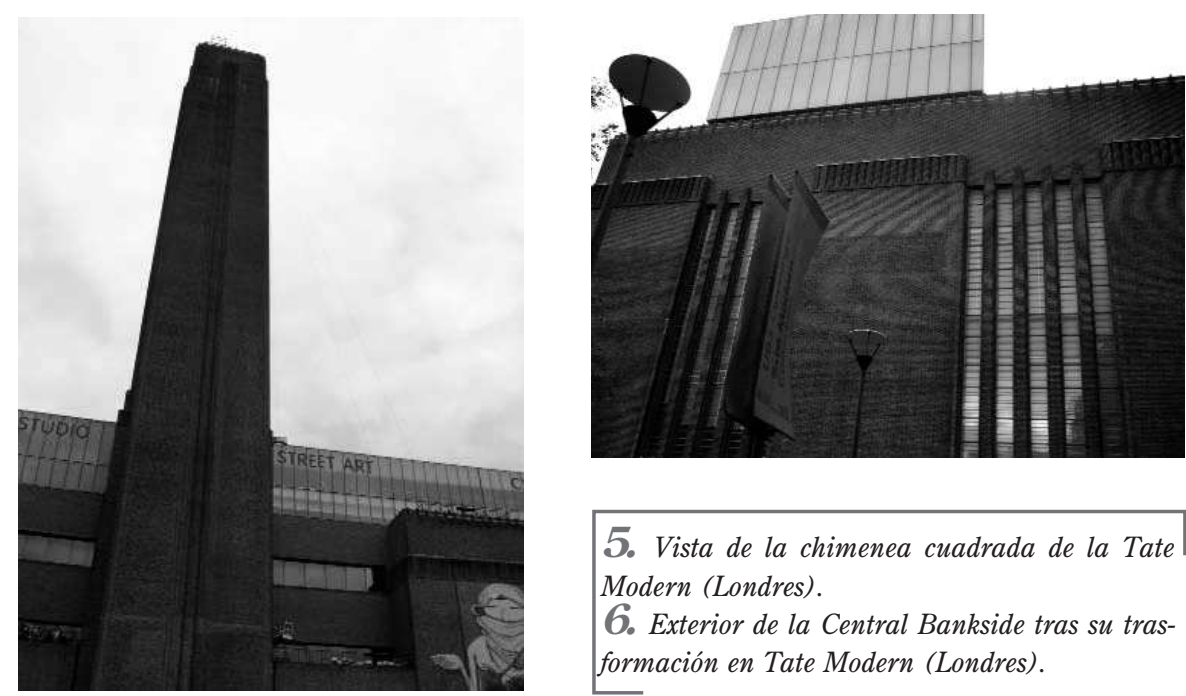

5. Vista de la chimenea cuadrada de la Tate Modern (Londres).

6. Exterior de la Central Bankside tras su trasformación en Tate Modern (Londres).

zos Herzog y De Meuron, consistió en la incorporación de un piso vidriado para albergar las áreas de descanso y un restaurante panorámico. Este nivel se concibió en forma de paralelepípedo transparente, posado sobre la cobertura de la estructura originaria y ligeramente retranqueado con respecto al volumen del edificio sustentante [6]. En el espacio principal de la central se desarrolló el recorrido expositivo ordenado según cuatro áreas temáticas, mientras que las salas de exposición -de diversas dimensiones- se caracterizaron por una sobria elegancia y por una total funcionalidad. Todo cuanto pertenecía y remitía a la historia industrial del lugar fue modificado para que la Central Eléctrica Bankside se transformase en una galería de arte contemporáneo, asumiendo su nueva identidad museística y permitiendo desarrollar de la mejor forma posible sus nuevas funciones; pues sólo una gran grúa y una serie de generadores que todavía funcionan -conservados en su lugar originario-, son hoy el único recuerdo que nos transporta al origen industrial del edificio. Scolaro apunta que las razones del éxito de la Tate Modern se deben al amplio relieve dado a la calidad del espacio, a su funcionalidad y a la fascinación que produce la unión entre el edificio industrial -técnico y desnudo- y el elemento artístico ${ }^{32}$; y parece ser que este triunfo ha llevado de nuevo a los arquitectos Herzog y De Meuron a proyectar la ampliación del museo, diseñando para ello una especie de "zigurat" en vidrio integrado por sucesivos bloques rectangulares superpuestos, sin orden aparente y configurando un total de once pisos ${ }^{33}$.

32 SCOLARO, M.: "Arquetipos y nuevas propuestas museísticas en Italia" en BELDA NAVARRO, C. y MARÍN TORRES, M.T. (eds.): La Museología y la Historia del Arte. Murcia, Universidad de Murcia, 2006, pág. 388.

33 La ampliación está prevista que sea inaugurada en el año 2012 con motivo de los Juegos Olímpicos que 


\section{El Centro Cultural Caixaforum (Barcelona).}

La fábrica de textil Casarramona fue construida por el arquitecto Josep Puig i Cadafalch en 1913, construcción con la que obtuvo ese mismo año el Premio Anual de Edificios Artísticos. El proyecto estaba inspirado en la majestuosidad romántica de un castillo medieval, formado por grandes espacios distribuidos orgánicamente alrededor de pasillos y con amplias naves inundadas de ventanales y claraboyas [7]. Pese al carácter utilitario del inmueble, en ningún momento el artista descuidó la importancia de los elementos estéticos y simbólicos del estilo modernista, dando como resultado una delicada decoración en hierro forjado y un uso innovador del ladrillo tradicional con una finalidad ornamental| ${ }^{34}$ [8].

Desde el año 2002, la fábrica se convirtió en el Caixaforum, un espacio donde albergar una de las colecciones privadas de arte contemporáneo más importantes de España, compuesta por unas setecientas obras desde la época del Dau al Set y el grupo El Paso hasta las últimas tendencias del arte contemporáneo internacional. El arquitecto Francisco Javier Asarta fue el encargado de dirigir las obras de rehabilitación en las que intervinieron otros profesionales de gran prestigio: Roberto Luna diseñó los espacios para ubicar el auditorio, la mediateca y unos almacenes, y Arata Isozaki fue el responsable de la construcción del acceso principal del nuevo centro cultural. Sus salas de exposición permanente se ubicaron en las antiguas naves de tejer e hilar y donde la colección se exhibe por áreas temáticas ofreciendo una interesante panorámica de la historia del arte español.

\section{EI Lingotto-Fiat (Turín).}

Otra de las tendencias hacia la reconversión de edificios industriales son los llamados espacios polifuncionales, donde se integran en el mismo complejo industrial infinidad de usos diversos, especialmente destinados para el ocio y la cultura. El ejemplo más representativo se produjo en la vieja fábrica Fiat-Lingotto de Turín (Italia), donde las vastas dimensiones de la planta automovilística permitieron crear un lugar donde poder proyectar una gran variedad de servicios destinados a la sociedad, pero sin llegar a romper la esencia de la arquitectura original.

El Lingotto fue diseñado por el ingeniero Matte Tucco, entre 1916 y 1933, y su construcción fue definida por Le Corbusier como uno de los más impresionantes edificios industriales. Una vez que la estructura quedó obsoleta se iniciaron una serie de discusiones acerca de su reutilización y fueron muchos los arquitectos importantes que plantearon sus ideas para la transformación del complejo. En 1986, mientras el edificio estaba destinado a diversas actividades culturales, la Fiat decidió encargar

se celebraran en la ciudad londinense.

34 La fábrica cerró en los años veinte, pasando a ser caballerizas de la policía tras la Guerra Civil. En 1963 fue comprada por la Fundación La Caixa y en el año 1976 fue declarada Monumento Histórico Artístico. 


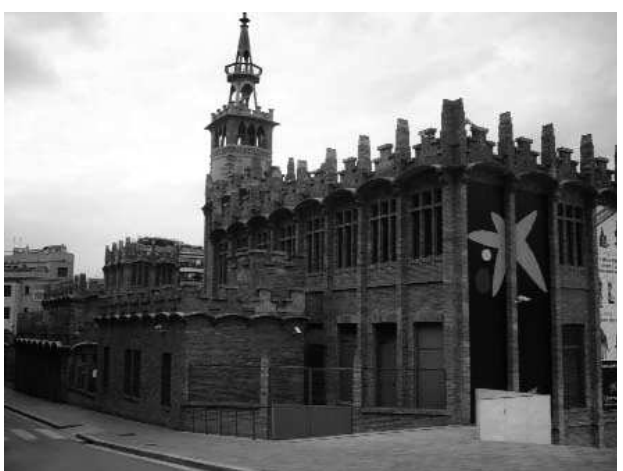

7. Vista exterior del Caixaforum (Barcelona).

8. Acceso a los espacios del nivel superior del Caixaforum (Barcelona).

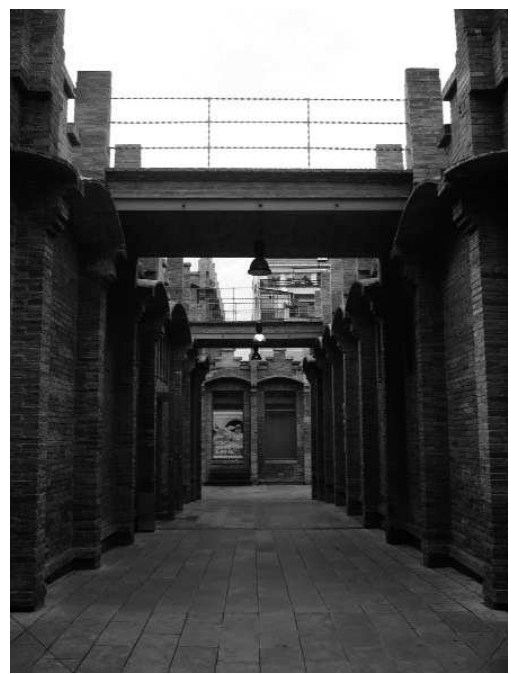

un nuevo proyecto arquitectónico a Renzo Piano. Desde 1991 hasta el año 2002, se produjo la reinvención definitiva del Lingotto a cargo de Piano, quien dio el máximo respeto a la impresionante estructura exterior como a la fascinante pista oval del tejado que servía para probar los vehículos recién fabricados. En los veinticinco mil metros cuadrados del complejo industrial distribuyó todo tipo de servicios lúdicos destinados a los ciudadanos: hotel, salas de reuniones, galerías comerciales, cines, auditorio e incluso la sede del Instituto Politécnico. Además se atrevió a incorporar nuevos espacios, como la construcción futurista en forma de media esfera transparente y la modernísima arquitectura colocada en el centro de la pista que simula una nave espacial recién aterrizada para albergar la pinacoteca con la colección donada por Giovanni Angelli.

En definitiva, la preservación del patrimonio industrial, especialmente el arquitectónico, ha planteado la necesidad de darles nuevos usos para su correcta conservación. La dotación de nuevas funciones a los edificios industriales ha favorecido las opciones de intervención en los monumentos, abriendo un amplio abanico de posibilidades de todo tipo: culturales, turísticas, comerciales y de una manera sorprendentemente relevante para fines museísticos. Este último destino ha presentado a lo largo y ancho del territorio europeo numerosos ejemplos con óptimos resultados y aportando una infinidad de soluciones para la puesta en valor tanto de los edificios industriales, de sus bienes muebles como del territorio donde se asientan. 


\section{ORIENTACIÓN BIBLIOGRÁfícA.}

AGUILAR, I.: "Restauración del patrimonio arqueológico industrial", en GUTIÉRREZ, R., CASTRO, F. y MARTÍN, M. (coords.): Preservación de la Arquitectura Industrial en Iberoamérica y España. Granada, Instituto Andaluz del Patrimonio Histórico, 2001, págs. 160-203.

ALONSO FERNÁNDEZ, L.: Museología y museografía. Barcelona, Ediciones del Serbal, 1999.

ÁLVAREZ ARECES, M.A.: "Musealización de espacios industriales: el patrimonio olvidado", en CALAF, R. y FONTAL, O. (coords.): Miradas al patrimonio. Gijón, Trea, 2006, págs. 328-356.

BOLAÑOS, M.: Historia de los museos en España: memoria, cultura y sociedad. Gijón, Trea, 1997.

BENITO DEL POZO, P.: "Patrimonio industrial y cultura del territorio", Boletín de la Asociación de Egresados y Graduados, n 34, Perú, 2002, págs. 213-227.

CANO SANCHIZ, J.M.: "La fábrica de la memoria. La reutilización del patrimonio arqueológico industrial como medida de conservación”, Antiqvitas, n 18-19, Córdoba, 2007, págs. 265-272.

CORRAO, M.: Musealizzazione dell'archeologia industriale. Materiali bibliografi. Palermo, Biblioteca Centrale della Facoltà di Architettura di Palermo, 2003.

GONZÁLEZ-VARAS, I.: Conservación de bienes culturales. Teoría, historia, principios y normas. Madrid, Cátedra, 2003.

HERNÁNDEZ HERNÁNDEZ, F.: Manual de Museología. Madrid, Síntesis, 1994.

HUMANES, A.: "La necesidad de un plan para el patrimonio industrial”, Bienes Culturales: Revista del Instituto del Patrimonio Histórico Español, n 7, Madrid, 2007, págs. 43-49.

LAYUNO ROSAS, M.A. Museos de arte contemporáneo en España. Del "palacio de las artes" a la arquitectura como arte. Gijón, Trea, 2004.

MATHIEU, C.: Orsay. L'espirit du lieu. París, Scala, 2007.

PARDO ABAD, C.J.: "La reutilización del patrimonio industrial como recurso turístico. Aproximación geográfica al turismo industrial”, Treballs de la Societat Catalana de Geografia, n 57, Barcelona, 2004, págs. 7-32.

SCOLARO, M.: "Arquetipos y nuevas propuestas museísticas en Italia" en BELDA NAVARRO, C. y MARÍN TORRES, M.T. (eds.): La Museología y la Historia del Arte. Murcia, Universidad de Murcia, 2006. 